\title{
O momento de Orfeu e Eurídice no rock brasileiro: uma reflexão sobre Loki, de Paulo Henrique Fontenelle
}

Loki: Arnaldo Baptista.

FONTENELLE, Paulo Henrique.

Brasil: Canal Brasil, 2008.

Loki é um documentário produzido pelo Canal Brasil sobre o músico e compositor Arnaldo Dias Baptista, nascido em São Paulo e que junto com o seu irmão Sérgio e Rita Lee criaram o conjunto brasileiro de rock Os Mutantes, na década de 1960. O filme resgata a carreira de Arnaldo desde esse período inicial até o momento recente, em que, depois de cair no esquecimento e ser de certa forma marginalizado, seu trabalho vem sendo reconhecido principalmente no exterior como um dos mais originais e inovadores no cenário do rock mundial. $\mathrm{O}$ documentário de Fontenelle vale não apenas pelo resgate em âmbito nacional desse reconhecimento mais amplo, mas sobretudo pelo arranjo inteligente e sensível de depoimentos do próprio Arnaldo, de colegas de trabalho, amigos e críticos, dos quais nos valemos para a escrita deste pequeno ensaio.

Depois da morte de Eurídice, Orfeu desce ao mundo dos mortos, aos infernos, a fim de recuperar a amada. É com sua lira que o poetamúsico-mago comove Hades e Perséfone. Numa passagem famosa de L'espace littéraire, Maurice Blanchot caracteriza essa passagem do mito dizendo que a arte é a potência que abre a noite. Através da arte, a noite se torna em boa medida íntima e acolhedora, mas num gesto paradoxal. Isso porque a tarefa de Orfeu não consiste simplesmente em descer às profundezas. Seu objetivo é resgatar a amada, trazê-la de volta ao dia. E Hades e Perséfone, que zelam pela permanência dos mortos debaixo da terra, só permitem a Orfeu realizar esse feito se, no caminho de volta, ele não olhar para trás, para a esposa. Orfeu desce ao centro mais tenebroso da noite, mas só pode fazê-lo emergir à tona virando-lhe as costas. ${ }^{1}$

Dessa forma, segundo a análise do crítico francês, o mito grego reconheceria que não se pode fazer uma obra (de arte) sem uma experiência da desmesura (da noite, das trevas, de um outro mundo, daquilo que quando se mira se perde). Tal experiência seria necessária à obra, que não pode apresentá-la, no entanto, senão dissimulando-a. No momento em que, durante o caminho de volta, Orfeu fraqueja, sente a necessidade de conferir se a esposa 0 acompanha, ele olha para ela e Eurídice se perde na sombra. Para Blanchot, esse movimento não é acidental, mas inevitável, porque não olhar para a esposa, não conferir se ela o seguia, seria também uma forma de perdê-la. Não há obra sem corte, perda e dissimulação, e o destino de Orfeu implica trair a obra, trair Eurídice, trair a noite, no mesmo movimento em que ele as salva ou tenta salvar.

A traição e a dissimulação acontecem porque, como diz Vinicius de Moraes na sua valsa (de Eurídice), a partida de Orfeu é uma "partida sem fim". Ela abriga uma saudade que é maior que a própria morte. Para que se possa apresentar essa saudade em uma obra, é preciso inevitavelmente romper com ela. Como o amor, a canção, mesmo se eterna, tem uma duração finita. E é esse o sentido da pergunta de Arnaldo Baptista à coreógrafa Regina Miranda: "Como é que você aguenta?". A pergunta nos espanta, e, seguindo o impulso mais imediato de todos nós que não somos Orfeu, que não somos poetas, Regina responde com outra pergunta: "Aguento o quê?".

Conforme no filme explica a coreógrafa, tal conversa teria originalmente se passado num 
mirante ao lado do teatro Ruth Escobar, em São Paulo. Depois da resposta espantada de Regina, Arnaldo teria então aberto muito os braços e dito: "porque isso tudo... eu me sinto completamente esburacado, por essa experiência, é como se as pessoas tivessem dançando e passando por todos os meus poros". É a experiência da desmesura, da partida sem fim e da saudade maior que a morte. A maneira com que a bailarina teve de preencher todos esses buracos foi abraçando o músico. Diz ela: "a gente ficou muito tempo abraçado e chorando... foi um momento de fundição". A duração desse momento, de um momento que é eterno, tem de ter um fim. No caso de Arnaldo, o fim, a traição, foi quase que literal. Uma tentativa de suicídio.

Mas venceu a força da dissimulação, e Arnaldo acorda nos braços de uma nova Eurídice. É assim que ele resume o acontecimento: "joguei o jogo mais alto, e parece um milagre que, de repente, eu acordei na cama da minha menina". Por minha menina ele se refere à Lucinha, uma fã, que a partir daí passa a preencher por um tempo a função de mulher amada na vida do poeta. Uma função certamente precária que ousa responder a um desafio infinito. "Amor que não tem pra comparar... é muito mais que amor de marido e mulher, um pouco parecido com amor de mãe, [mas também] uma sina" - declara Lucinha. Lucinha que é uma das faces dessa eterna Eurídice do poeta, que o poeta tenta resgatar, ciente, entretanto, "da enorme diferença que existe entre o homem e a mulher" (palavras de Arnaldo).

Lucinha, Martha Mellinger, Rita Lee e a mãe pianista, todas elas são faces diferentes de uma totalidade nunca inteiramente presente: a Eurídice de Orfeu. Muito consciente da importância dessa diferença que ao mesmo tempo o instiga e o ilude, Arnaldo faz a seguinte observação: em todas as comparações que sempre se fizeram entre Os Mutantes, os Beatles e os Rolling Stones, esqueceuse de um ponto importante. No caso dessas duas outras bandas, elas não tinham mulher entre os integrantes, não tinha o "lado circense", aquilo que a Rita trazia em termos de "roupas, instrumentos malucos, um lado colorido". Arnaldo, num passo ousado que talvez não pudesse deixar de ser um erro, trouxe a mulher para dentro do grupo. Aquela com quem, na lembrança dos amigos, ele tinha "uma relação de muito carinho, atávica, uma relação de irmão e irmã - o típico casal que não dá certo para casar".

Isso explicaria talvez por que, no pouco tempo que durou, Os Mutantes conseguiram alcançar tal originalidade que muitos músicos consideram ser mais significante que a das duas outras bandas referidas. O mínimo que se pode dizer é que eles criaram algo que até então não existia no cenário do rock brasileiro. Nas palavras de Tárik de Souza,

\section{[...] até então, era um rock primário que era} feito no Brasil. Além de poucos acordes, era um rock muitas vezes copiado... Com Os mutantes, o rock ganha uma identidade brasileira... Isso não é pouca coisa, você pegar uma música estrangeira e dar uma identidade brasileira, realmente precisa ter um estofo musical... capacidade de se projetar na música... Foi isso que deu a autenticidade que Os Mutantes têm

Sabe-se que essa capacidade de se projetar na música, de se expressar na obra, foi algo que Arnaldo aprendeu a fazer desde muito cedo, no contato com a mãe pianista. Está aí a raiz de uma relação com a música que, como diz Lobão, faz dessa arte "uma maneira de viver realmente muito além de ser um ganha-pão". A música é poder de transformação. Ela é Orfeu encantando os animais selvagens. É também "a fusão do homem com o artista, do artista com o homem". Nas palavras de Zélia Duncan, "Arnaldo é a balada do louco". Observar do mirante e sentir-se atravessado, em todos os poros, por pessoas que passam por nós e dançam. Uma experiência difícil, senão impossível. Numa lucidez insuspeita, Arnaldo confessa: "é tão difícil dizer all you need is love... cada um de nós é totalmente diferente".

Mas ele faz "a maior força possível" para alcançar essa totalidade que nunca nos é inteiramente dada, que possibilitaria acolher o outro na sua diferença irredutível, resgatar, acolher a noite mais infernal e tenebrosa. A resposta de Rita Lee - ela que foi, no dizer do próprio Arnaldo, o outro elemento-chave d'Os Mutantes - talvez não pudesse ter sido outra. Como é que se pode falar de uma ferida infinita? Jamais falando dela, virando-lhe as costas, dissociando-a numa jornada de adeus (que não é outra coisa senão uma forma muito justa de falar). A cantora também tinha uma pianista na família e teria estudado com ninguém menos que Madga Tagliaferro. ${ }^{2}$ Seja como for, o aparente "escapismo" da roqueira brasileira, sua recusa de ser engajada, está longe de ser um índice de menoridade artística. É justamente aquilo que complementa Orfeu e sem o que Orfeu não é nada. É a capacidade mais visceral de dissimulação, de fantasia. Sem essa capacidade, mal se pode aceitar o convite àquilo que os 
ingleses chamam de exhilaration e os franceses de ivresse, ${ }^{3}$ termos que também não deixam de ser uma boa tradução para aquilo que em português chamamos de saudade. Uma vez aceito, só então o convite possibilitou um momento, esse momento que não apenas passou, mas está sempre passando, de uma forma que, concretamente onde está, nunca deixa de passar: o momento de Orfeu e Eurídice, no rock brasileiro.

\section{Notas}

1 Maurice BLANCHOT, 1955, p. 225.

${ }^{2}$ Henrique BARTSCH, 2006, p. 22 e p. 36.
${ }^{3}$ É o que está no âmago da experiência estética de um Proust. Ver, por exemplo, o momento epifânico da entrada do narrador no Hotel dos Guermantes, em Marcel PROUST, 1990, p. 173-174.

\section{Referências}

BARTSCH, Henrique. Rita Lee mora ao lado. São Paulo: Panda Books, 2006.

BLANCHOT, Maurice. L'espace littéraire. Paris: Gallimard, 1955.

PROUST, Marcel. Le temps retrouvé. Malesherbes: Gallimard, 1990.

Alessandro Zir Universidade Federal do Rio Grande do Sul 


\section{Errata}

\section{Número 2 - 2012}

\section{Pág. 583}

No seguinte trecho da resenha "O momento de Orfeu e Eurídice no rock brasileiro: uma reflexão sobre Loki, de Paulo Henrique Fontenelle", de Alessandro Zir, saiu "os seus irmãos" em vez de "o seu irmão": Loki é um documentário produzido pelo Canal Brasil sobre o músico e compositor Arnaldo Dias Baptista, nascido em São Paulo e que junto com o seu irmão Sérgio e Rita Lee criaram o conjunto brasileiro de rock Os Mutantes, na década de 1960. 